Supporting Information

\title{
Constructing a stable Si-N-enriched interface boosts lithium storage kinetics in a silicon-based anode
}

Zhen Yang, Minxia Jiang, XinWang, Yingxinjie Wang, Minhua Cao*

Key Laboratory of Cluster Science, Ministry of Education of China, Beijing Key Laboratory of Photoelectronic/Electrophotonic Conversion Materials, School of Chemistry and Chemical Engineering, Beijing Institute of Technology, Beijing 100081, P. R. China

E-mail: caomh@bit.edu.cn 


\section{Kinetics and quantitative analysis calculations}

To quantitatively distinguish the capacitive and diffusion-controlled contributions to current, $\mathrm{CV}$ curves at a series of sweep rates were tested. Generally, the relationship between the measured peak current $(i)$ and sweep rate $(v)$ in a $\mathrm{CV}$ scan follows the following formula: ${ }^{1}$

$$
\begin{gathered}
i=\mathrm{a} v^{b} \\
\text { then, } \log (i)=\log (\mathrm{a})+b \cdot \log (v)
\end{gathered}
$$

Apparently, the $b$ value can be obtained by fitting slope of the $\log (i)$ versus $\log (v)$ profile. When the $b$ value is 0.5 , it demonstrates a diffusion-controlled behavior, while the $b$ value of 1.0 corresponds to a capacitive behavior. The capacitive contribution and diffusion-controlled contribution can be further quantitatively distinguished assuming that the current $(i)$ is a combination of the capacitor-like and diffusioncontrolled processes according to:

$$
i=k_{1} v+k_{2} v^{1 / 2}
$$

We can calculate the capacitive and diffusion limited contributions by determining $k_{1}$. In addition, the diffusion kinetics of $\mathrm{Li}^{+}$was further studied based on the $\mathrm{CV}$ measurement value. According to the Randles-Sevchik equation below: ${ }^{2}$

$$
I_{p}=2.69 \times 10^{5} \mathrm{An}^{3 / 2} C_{0} D_{\mathrm{Li}}{ }^{+1 / 2} v^{1 / 2}
$$

where $\mathrm{n}$ is the number of transfer electrons per redox reaction, $A$ is the surface area of the electrode, $C_{0}$ is the molar concentration of $\mathrm{Li}^{+}$in the anode, and $\mathrm{DLi}^{+}$is the chemical diffusion coefficient of $\mathrm{Li}^{+}$. As the electrode in this work is chosen with same active material and tested in the same procedure, the Randles-Sevchik equation can be simplified and $D_{\mathrm{Li}}{ }^{+}$is determined by the slope of the peak current $\left(I_{\mathrm{p}}\right) v s$. the square root of scan rate $\left(v^{1 / 2}\right)$.

Based on the data of Warburg resistances, the $D_{\mathrm{Li}}{ }^{+}$of $\mathrm{Li}^{+}$can be calculated using the following equation: ${ }^{3}$

$$
\begin{aligned}
& D_{L^{+}}=\frac{R^{2} T^{2}}{2 A^{2} n^{4} F^{4} C^{2} \sigma^{2}} \\
& Z^{\prime}=R_{\mathrm{D}}+R_{\mathrm{L}}+\sigma \omega^{-1 / 2}
\end{aligned}
$$


where $R$ represents the gas constant, $T$ represents the absolute temperature, $A$ represents the surface area of the anode, $n$ represents the number of electrons, $F$ represents the Faraday constant, and $C$ represents the concentration of sodium ions. $\sigma$ is the Warburg factor related to charge diffusion, which is the slope of the line of $Z^{\prime}$ vs $\omega^{-1 / 2}$. 

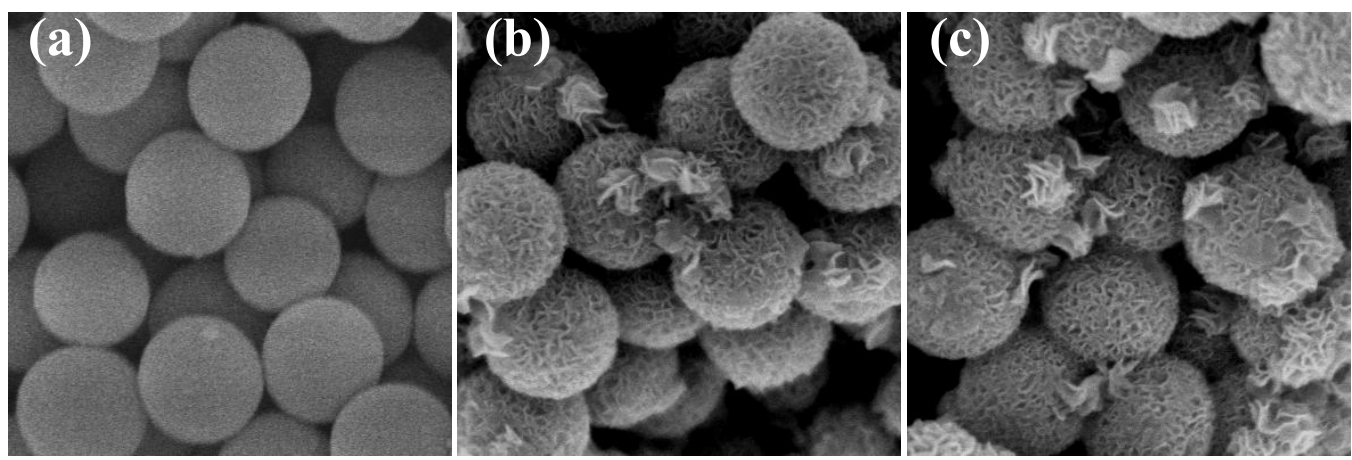

Figure S1. FE-SEM images of $\mathrm{SiO}_{2}(\mathrm{a}), \mathrm{Zn}_{2} \mathrm{SiO}_{4}$ (b) and $\mathrm{Zn}_{2} \mathrm{SiO}_{4} @ \mathrm{PDA}$ (c) nanospheres.
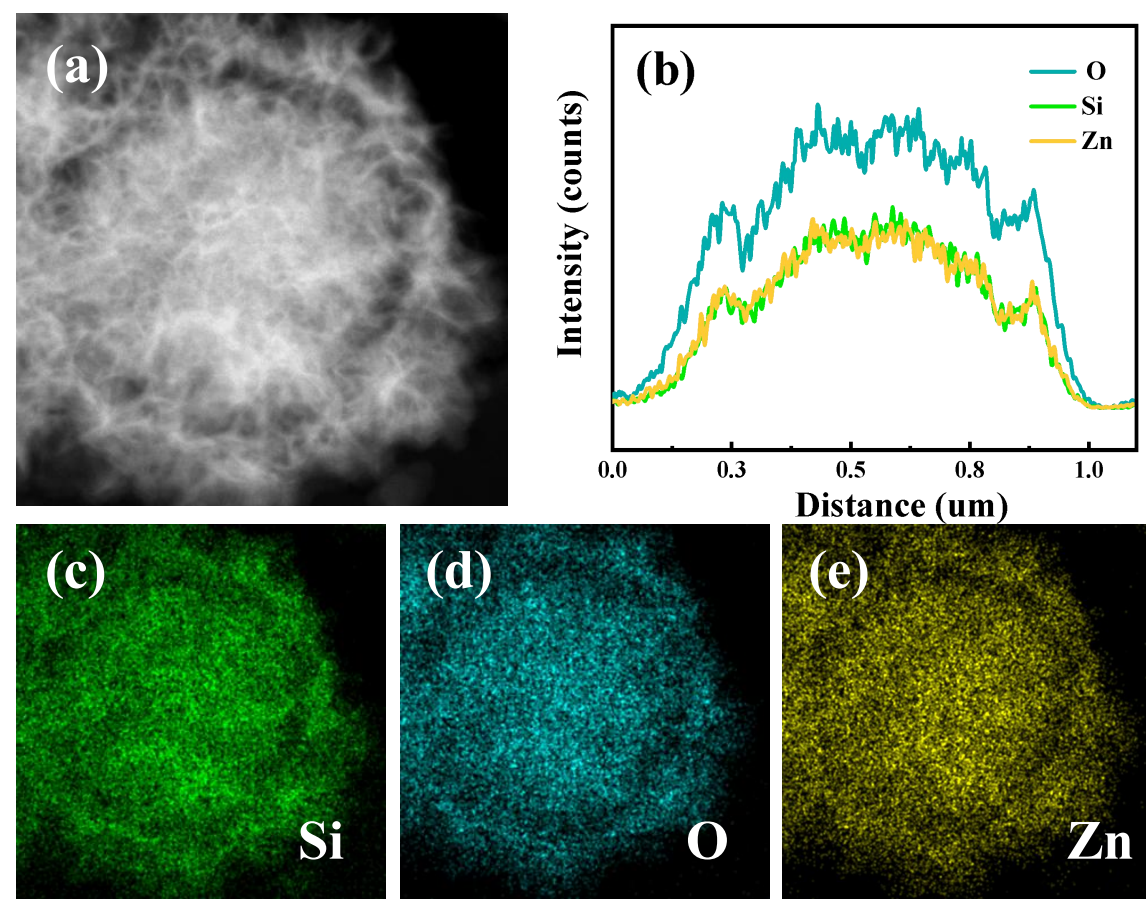

Figure S2. (a) TEM image of $\mathrm{Zn}_{2} \mathrm{SiO}_{4}$ and (b) the corresponding line-scan profiles. (c-e) Elemental mapping images for $\mathrm{Si}, \mathrm{O}$ and $\mathrm{Zn}$, respectively. 

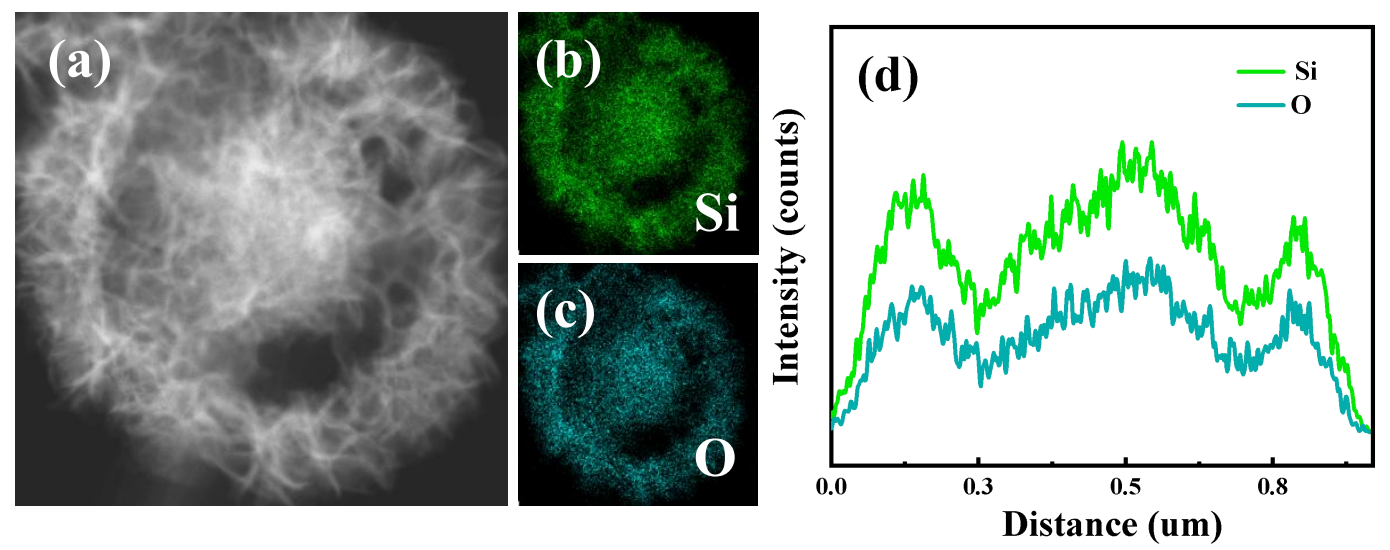

Figure S3. (a) TEM image of $\mathrm{SiO}_{\mathrm{x}}$ and (b, c) the corresponding elemental mapping images for $\mathrm{Si}$ and $\mathrm{O}$, respectively. (d) Line-scan profiles of $\mathrm{SiO}_{\mathrm{x}}$.
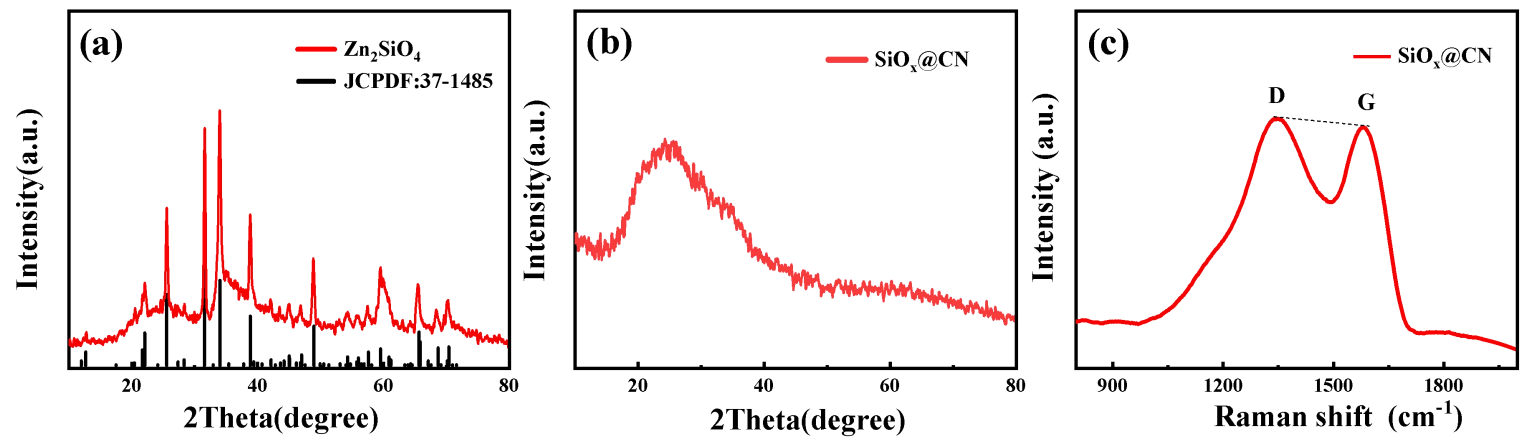

Figure S4. $(a, b) X R D$ patterns of $\mathrm{Zn}_{2} \mathrm{SiO}_{4}$ and $\mathrm{SiO}_{x} @ \mathrm{NC}$. (c) Raman spectrum of $\mathrm{SiO}_{\mathrm{x}} @ \mathrm{NC}$. 

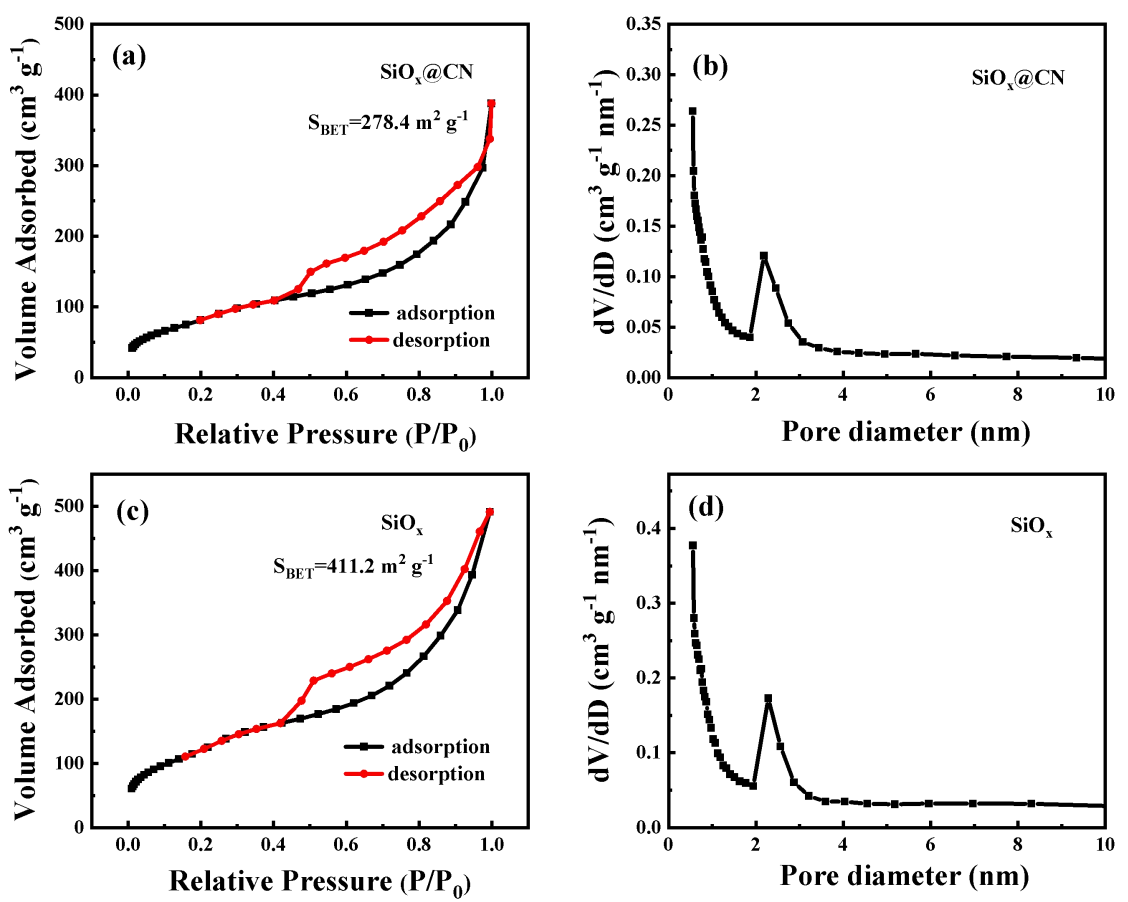

Figure S5. (a,c) $\mathrm{N}_{2}$ adsorption/desorption isotherms and (b,d) pore size distribution curves of $\mathrm{SiO}_{\mathrm{x}} @ \mathrm{NC}$ and $\mathrm{SiO}_{\mathrm{x}}$.

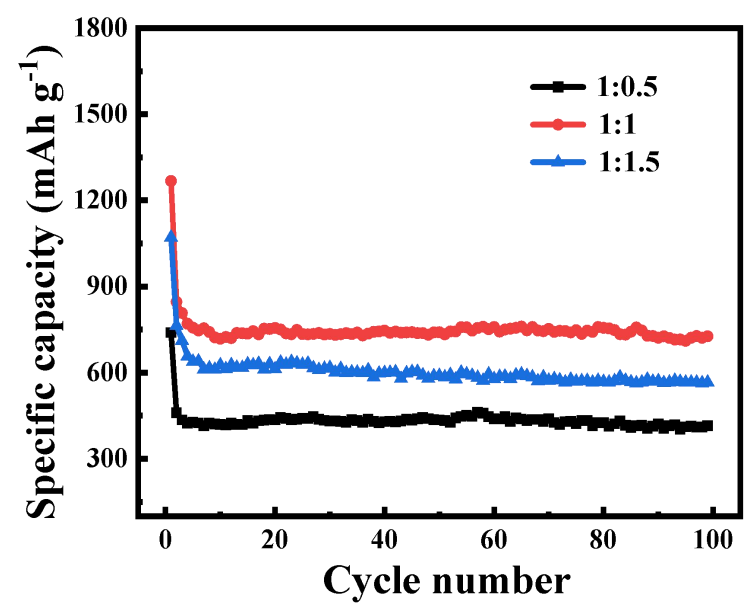

Figure S6. Cycling performances of $\mathrm{SiO}_{\mathrm{x}} @ \mathrm{NC}$ obtained with different PDA contents at $0.1 \mathrm{~A} \mathrm{~g}^{-1}$. 


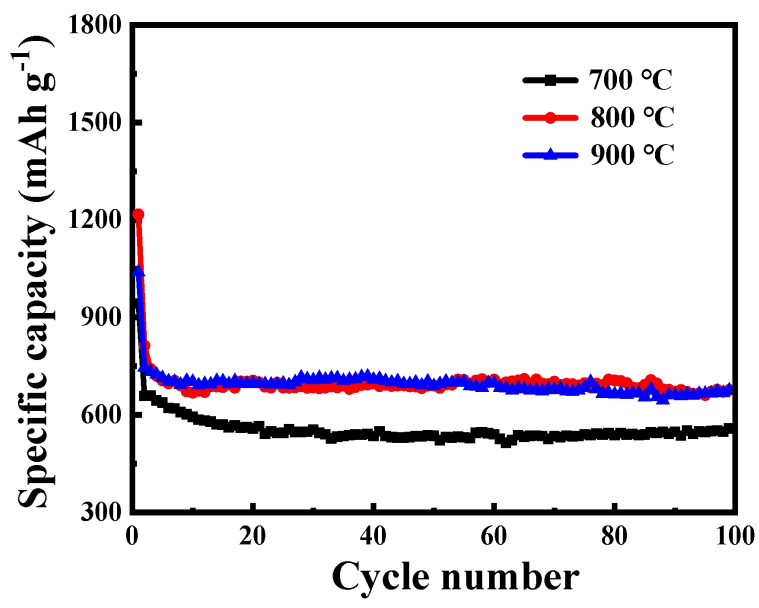

Figure S7. Cycling performance of $\mathrm{SiO}_{\mathrm{x}} @ \mathrm{NC}$ obtained at different pyrolysis temperatures at $0.1 \mathrm{~A} \mathrm{~g}^{-1}$.

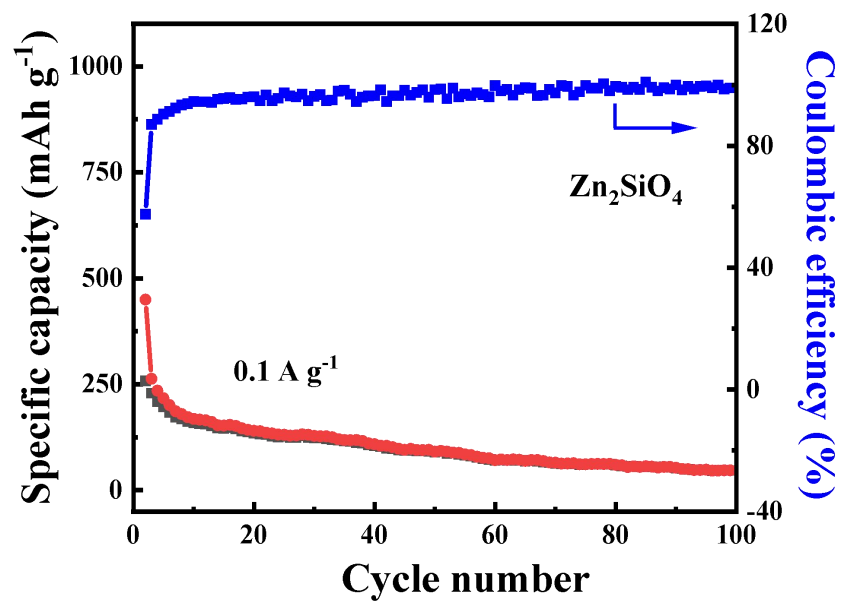

Figure S8. Cycling performance of $\mathrm{Zn}_{2} \mathrm{SiO}_{4}$ under $0.1 \mathrm{~A} \mathrm{~g}^{-1}$. 


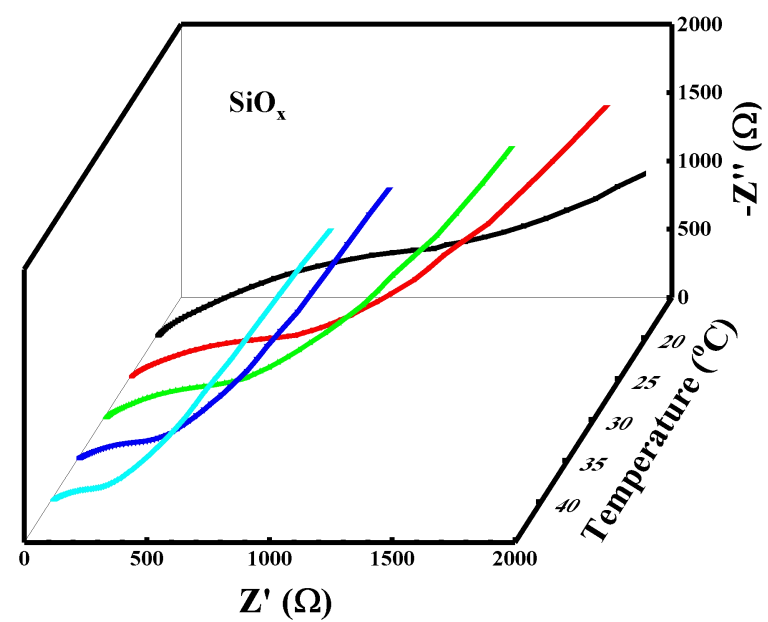

Figure S9. EIS spectra of $\mathrm{SiO}_{\mathrm{x}}$ at different temperatures.

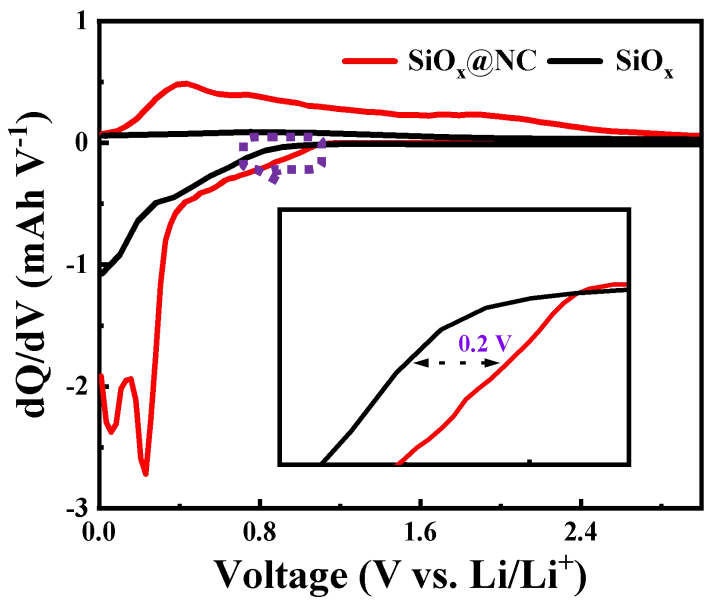

Figure S10. The differential capacity vs. voltage $(\mathrm{dQ} / \mathrm{dV})$ curves of of $\mathrm{SiO}_{\mathrm{x}} @ \mathrm{NC}$ and $\mathrm{SiO}_{\mathrm{x}}$ for 10 cycles . 


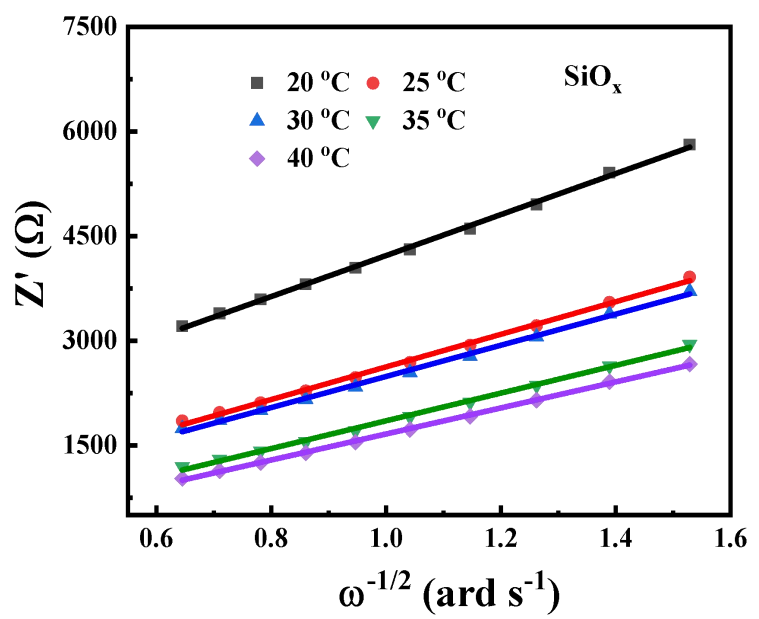

Figure S11. The linear relationship of $Z^{\prime} v \mathrm{~s} \omega^{-1 / 2}$ for $\mathrm{SiO}_{\mathrm{x}}$.

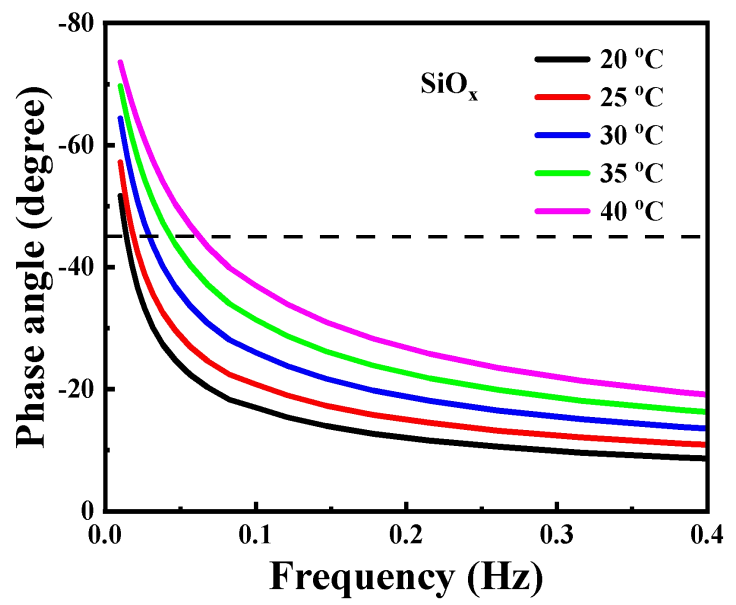

Figure S12. Bode plots of phase angle versus frequency at different temperatures for $\mathrm{SiO}_{\mathrm{x}}$. 

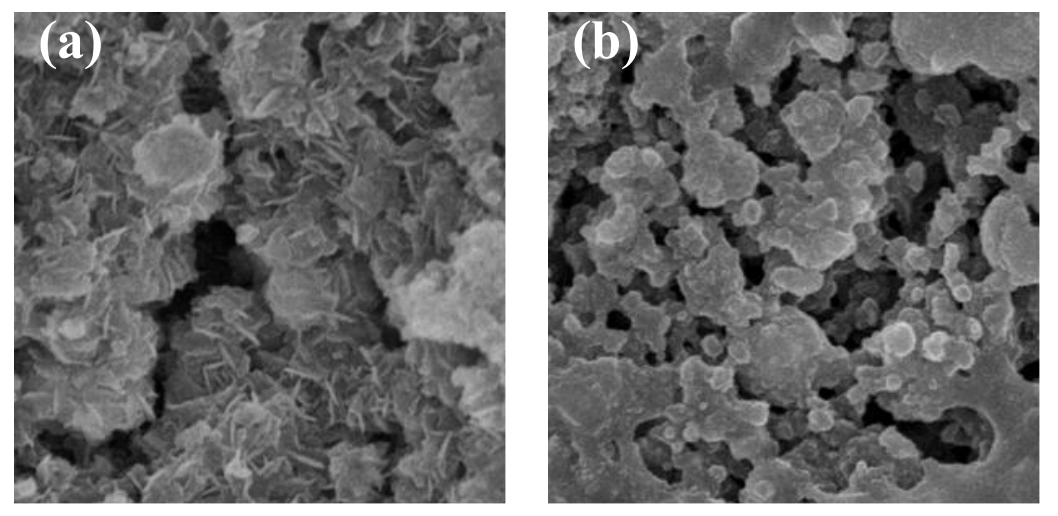

Figure S13. FE-SEM images of $\mathrm{SiO}_{\mathrm{x}} @ \mathrm{NC}(\mathrm{a})$ and $\mathrm{SiO}_{\mathrm{x}}(\mathrm{b})$ after 100 cycles.
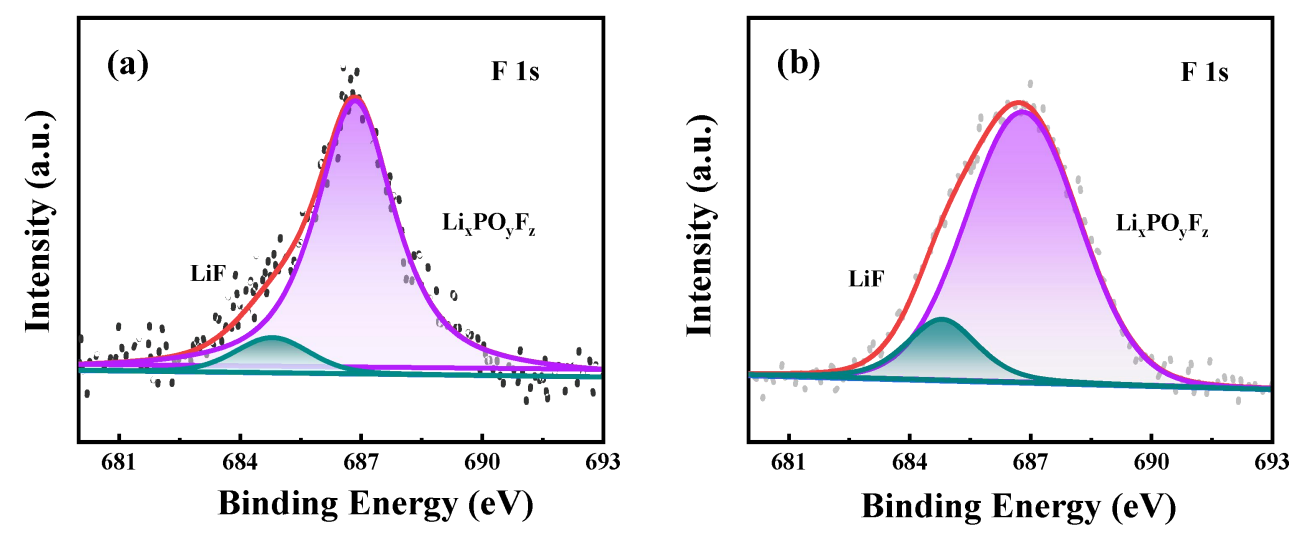

Figure S14. High-resolution XPS spectra of F 1s for $\mathrm{SiO}_{\mathrm{x}} @ \mathrm{NC}(\mathrm{a})$ and $\mathrm{SiO}_{\mathrm{x}}(\mathrm{b})$. 


\section{References}

(1) Jiang, Y.; Li, Y.; Zhou, P.; Lan, Z.; Lu, Y.; Wu, C.; Yan, M. Ultrafast, Highly Reversible, and Cycle-Stable Lithium Storage Boosted by Pseudocapacitance in Sn-Based Alloying Anodes. Adv. Mater. 2017, 29, No. 1606499.

(2) Zhang, B.; Yu, Y.; Huang, Z.; He, Y. B.; Jang, D.; Yoon, W. S.; Mai, Y. W.; Kang, F.; Kim, J. K. Exceptional Electrochemical Performance of Freestanding Electrospun Carbon Nanofiber Anodes Containing Ultrafine $\mathrm{SnO}_{\mathrm{x}}$ Particles. Energ. Environ. Sci. 2012, 5, 9895-9902.

(3) Yang, Y.; Zhao, X.; Wang, H. E.; Li, M.; Hao, C.; Ji, M.; Ren, S.; Cao, G. Phosphorized $\mathrm{SnO}_{2} /$ Graphene Heterostructures for Highly Reversible Lithium-Ion Storage with Enhanced Pseudocapacitance. J. Mater. Chem. A 2018, 6, 3479-3487. 